\title{
Returning lands to nature
}

\author{
Land-use-induced ecosystem reduction and degradation has profound impacts on the Earth system. Proceeding \\ with currently unsustainable land use may jeopardize climate and ecosystem restoration targets.
}

T his year, both Earth Day and World Environment Day highlighted ecosystem restoration as the theme to set out the United Nations Decade on Ecosystem Restoration. Natural ecosystems provide a broad range of beneficial services, many of which are critical for human well-being and for tackling environmental challenges such as the biodiversity and climate crises. However, rapid expansion of urban and agricultural lands has significantly transformed the natural landscape. Globally, less than half of the terrestrial realm remains intact ${ }^{1}$. Over as little as the past six decades, almost a third of the global land area has been affected by land-use change ${ }^{2}$.

Overexploitation of land resources has squeezed the space for nature and deteriorated the quality of ecosystems and the services they provide. The Earth system, in which ecosystems play a unique role, has also experienced significant changes. With this issue, we present a collection of recent articles that explore the trend and impacts of land-use change, as well as the resultant ecosystem degradation, to highlight the urgent need for worldwide actions on land restoration.

Land-use change greatly impacts regional and global climate. Before the advent of industrial fossil fuel burning, land-use change was the largest source of greenhouse gas (GHG) emissions ${ }^{3}$. In 2017, emissions associated with land management and land use are estimated to account for $25 \%$ of total anthropogenic GHG emissions ${ }^{4}$. Latin America, Southeast Asia and sub-Saharan Africa have the largest land-use emissions, due to the rapid and extensive growth of agricultural production ${ }^{4}$. More direct and acute climate impact has been found in tropical mountainous areas. For regions where deforestation is extensive, local temperature anomalies can reach up to $2^{\circ} \mathrm{C}$ (ref. ${ }^{5}$ ).

Conversely, preserving and restoring ecosystems via sustainable land-use policies can achieve substantial climate benefits. Two Articles published in this issue give quantitative evidence. By directly comparing GHG emissions from years of in situ measurements at a pair of peatlands in Indonesia, Deshmukh et al. find that an intact peatland released only half of the GHG emissions as its degraded counterpart. In another Article, Meier et al. use an observation-based statistical model to show that forestation of rainfed agricultural lands across Europe can increase continental summertime precipitation by more than $7 \%$, substantially offsetting the projected precipitation decrease from climate change.

Ecosystem degradation induced by deforestation and agricultural expansion may also impair valuable environmental services. In Africa, tropical forests are experiencing severe degradation from human activities such as logging, road development and small-scale farming that create fragmentation at forest edges. An Article in this issue finds that these degraded forests had a carbon deficit of more than four billion tons in aboveground biomass based on high-resolution satellite data. The edge effect was greater in native forests than plantations. Deforestation also leads to soil degradation in the tropics, strongly affecting soil functions such as nutrient storage, erosion resistance and water storage, drainage and filtration ${ }^{6}$.

As ecosystems degrade, land-use effects may cascade to biological communities. For example, converting tropical rainforests to agricultural systems in Indonesia is found to reduce biomass and species richness of taxa across trophic levels, from microorganisms to birds, with increasing magnitude of reduction at higher trophic levels ${ }^{7}$. What's more concerning is that such biomass and biodiversity losses may not be able to completely recover even a century after agricultural abandonment ${ }^{8}$.

The UN Decade on Ecosystem Restoration could not have come at a better moment, as it becomes ever clearer that the climate and species extinction crises are intertwined issues that need to be tackled together ${ }^{1}$. To keep global temperatures below a $1.5^{\circ} \mathrm{C}$ increase, it is estimated that conserving all existing native ecosystems will be needed ${ }^{1}$. Degradation may take decades to restore, and even then ecosystem and environmental functions may still significantly deviate from those under intact conditions ${ }^{6}$.

To achieve the climate and ecosystem restoration targets, land-use policies hold the key. In particular, there is an urgent need for a unified effort towards land preservation and restoration across the globe. The Global North and South have recently been found to have diverging land-use change processes over the past six decades: afforestation and agricultural abandonment have dominated in the Global North, including China, leading to increased forest areas and reduced cropland areas, whereas deforestation and agricultural expansion have resulted in the opposite land-use trend in the Global South ${ }^{2}$. Global trade on agricultural products is an important and growing driver of this geographic divergence ${ }^{2,9}$. With the growing number of global political and economic powerhouses making more ambitious commitments on climate mitigation, such as carbon neutrality and ecosystem restoration, it is important to make sure that these commitments are not delivered at the cost of environmental and ecosystem deterioration in less-developed regions.

Humans have been modifying natural landscapes for thousands of years. These land-use activities have provided food, water and other essential living products, helping improve our quality of life. But long-term unsustainable expansion has ongoing negative impacts on the Earth system and its ecosystem services. These impacts have in turn jeopardized living conditions and put the right of younger generations to development at risk ${ }^{10}$. Action will be needed fast before more irreversible catastrophic ecosystem and climate consequences arise.

Published online: 5 July 2021

https://doi.org/10.1038/s41561-021-00795-0

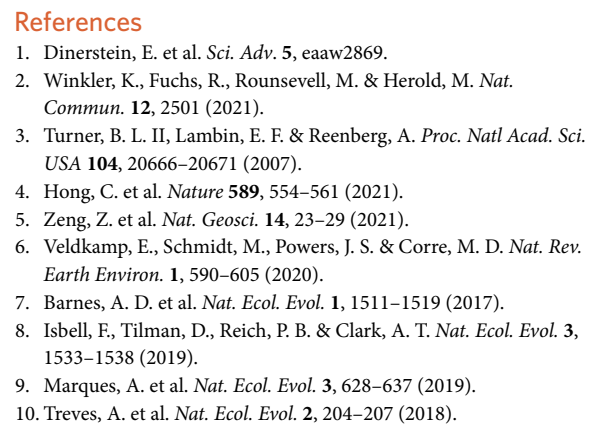

